\section{The evaluation of conservation practice placement in the Little River Experimental Watershed using geographic information systems}

\author{
J.R. Settimi, D.G. Sullivan, and T.C. Strickland
}

\begin{abstract}
The Conservation Effects Assessment Program Watershed Assessment Study is a joint effort between the USDA Natural Resources Conservation Service (NRCS) and the USDA Agricultural Research Service to evaluate the effectiveness of federally funded conservation programs. In response to this initiative, a 26-year history of NRCS conservation practice placement (1980 to 2006) was evaluated for the Little River Experimental Watershed (LREW) in the southeastern coastal plain of Georgia. To accomplish this task, currently available geographic databases were integrated and queried to assess levels of commonly adopted practices and to evaluate factors affecting practice placement. Databases included (1) USDA NRCS Conservation Practice Database for the LREW, (2) USDA NRCS Soil Survey Geographic Database (SSURGO), and (3) $30 \mathrm{~m}$ (98 ft) digital elevation maps. Nearly 50\% of all cropland fields in the LREW were delineated as having participated in conservation programs. Practices were predominantly used for water quality and erosion control. Sixty to $65 \%$ of the fields $(77 \%$ of land area) implemented soil erosion and/or water quality control practices in high resource concern areas. Results showed that hydrologic group and proximity to a water body, rather than slope class, were the predominant factors in conservation practice placement. Using a subwatershed database having complete field coverage of four LREW subwatersheds (with and without USDA NRCS assistance), geographic information system databases were queried to evaluate the adoption and placement of erosion control practices that were visible in a 2005 digital orthoquad. Forty-seven percent of all fields in the subwatershed database had implemented visible erosion control-specific conservation practices. and implementation was linearly related to slope class $\left(r^{2}=0.64, p<0.10\right)$. Fields identified as having participated in federally funded conservation programs coincided with high resource concern areas $35 \%$ of the time.
\end{abstract}

Key words: Conservation Effects Assessment Project (CEAP) — conservation programLittle River Experimental Watershed (LREW) - Natural Resources Conservation Service (NRCS)

In 2003, the USDA Natural Resources Conservation Service (NRCS) and USDA Agricultural Research Service launched the Conservation Effects Assessment Project (CEAP) Watershed Assessment Study (WAS) to quantitatively evaluate conservation practice benefits at the watershed scale (Soil and Water Conservation Society 2006). This project was established to (1) better quantify conservation practice benefits, (2) provide policymakers with tools to track benefits, practices and services, as well as developing future strategies.

The primary goal of the current manuscript is to evaluate a 26-year history of conservation practice placement in the Little River Experimental Watershed (LREW). The LREW is located in south central Georgia and is one of the original benchmark watersheds for CEAP WAS. This manuscript directly addresses the following specific suggestions made by the 2006 CEAP Blue Ribbon Panel: (1) evaluate the effectiveness of a well-advised technical staff in introducing conservation practices or farming systems where they are most needed and (2) monitor program implementation. More importantly, knowledge of conservation practice placement may be used in the future to refine hydrologic modeling scenarios necessary to define the magnitude and extent of environmental problems and to reevaluate conservation strategies.

These efforts were made possible by the creation of two CEAP-specific databases: Sustaining the Earth's WatershedsAgricultural Research Data System (STEWARDS) and a locally developed Conservation Practice Database for the LREW. The STEWARDS database was a national effort across CEAP benchmark watersheds to establish a centralized database regarding soils, hydrology, climate, topography, management, and economics (Hatfield et al. 2002). The STEWARDS database is dynamic, incorporating archived databases as well as new data in a uniform format (Steiner et al. 2008; Sadler et al. 2008). The STEWARDS database has since become the foundation of the CEAP-WAS initiative (Mausbach and Dedrich 2004).

The LREW conservation practice database (CPD) serves as a geographic information database of all fields that received USDA NRCS conservation practice assistance between 1980 to 2006 (Sullivan and Batten 2007). While it has become common for the USDA NRCS to digitize conservation practice placement over the last three to five

John R. Settimi is a professor of agronomy in the School of Agriculture and Natural Resources, Abraham Baldwin Agricultural College, Tifton, Georgia. Dana G. Sullivan is a soil scientist and remote sensing specialist with TurfScout LLC, Tifton, Georgia. Timothy C. Strickland is a research leader at the Southeast Watershed Research Laboratory, USDA Agricultural Research Service, Tifton, Georgia. 
years, nearly all of the historic information regarding conservation practice placement in the LREW was only recently converted into a digital format. The LREW CPD provides a foundation by which predominant conservation practices, trends in practice adoption, and most importantly, practice placement can be evaluated using a geographic information system (GIS). While conservation practice placement was evaluated posthoc in this study, it is expected that it could be used for selection of future candidates for inclusion in federal conservation programs and outreach efforts to those producers not currently employing conservation practices in high resource concern areas.

\section{Materials and Methods}

Study Site. The LREW, near Tifton, Georgia, is approximately $334 \mathrm{~km}^{2}$ (129 $\mathrm{mi}^{2}$ ) and is located in the headwaters of the Upper Suwannee River Basin (figure 1). Establishment of the LREW began in 1967, and it was fully instrumented in 1971 (Bosch and Sheridan 2007). Since that time, detailed records, including rainfall patterns, stream gauges, stream flows, and water quality/quantity, have been maintained. These data have been used specifically to assess the impacts of agricultural land management on water quality/quantity in a typical southeastern coastal plain system (Lowrance et al. 1985; Feyereisen et al. 2007, 2008).

The LREW is a typical southeastern coastal plain watershed, consisting primarily of low-gradient streams and sandy to sandy loam surface soil textures (USDA NRCS 1983). Land use within the watershed is made up of $31 \%$ row crop agriculture, $10 \%$ pasture, $28 \%$ riparian forest, $22 \%$ upland forest, and $7 \%$ urban area based on the classification of 2003 Landsat 5 imagery (Bosch et al. 2006). Agricultural areas consist predominantly of row crops (cotton [Gossypium hirsutum L.], corn [Zea mays L.], peanut [Arachis hypogaea]) and vegetable production. A characteristic feature of the LREW is up to $79 \%$ of total runoff loss from December through May occurs as lateral subsurface flow. Lateral subsurface flow has been observed to account for as much as 99\% of total nitrate-nitrogen loss from the LREW (Hubbard and Sheridan 1983).

The Geographic Databases. A series of preexisting databases were organized within a GIS to determine predominantly used conservation practices and to categorize soil and

\section{Figure 1}

Little River Experimental Watershed boundaries, historical database field boundaries, and subwatershed field boundaries.

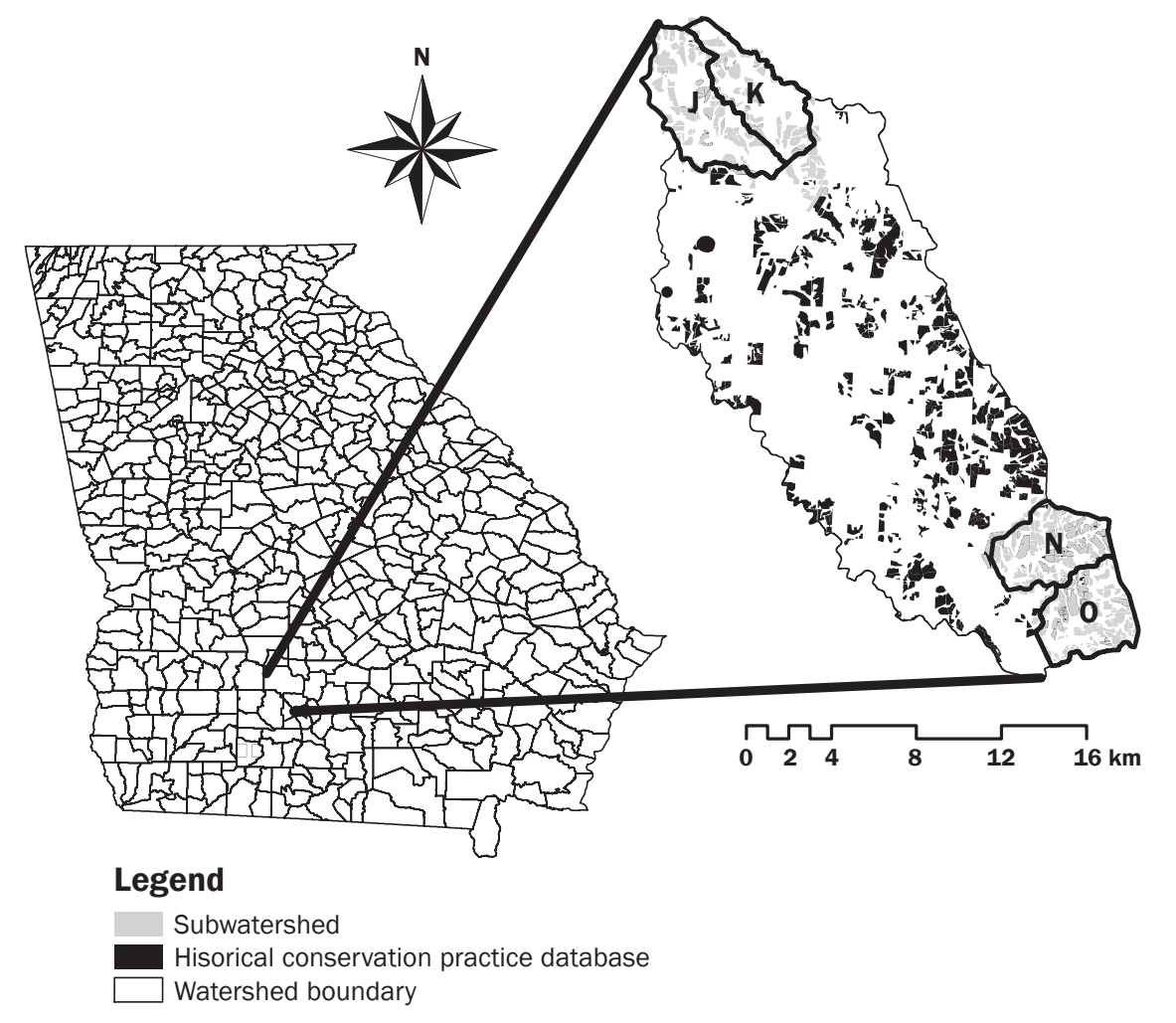

landscape features that will be used to determine high resource concern areas. Databases included the LREW CPD, the USDA NRCS Soil Survey Geographic Database (SSURGO), and $30 \mathrm{~m}$ (98 ft) digital elevation maps.

The LREW CPD contains specific information on USDA NRCS practice codes and descriptions, programs under which a practice was implemented, acreage, date of completion, and cost of the practice to the land owner. There were a total of 640 fields within the LREW CPD, and 457 of those fields were identified as croplands sites implementing one or more cropland, water quality, or erosion-control practices. The remaining 183 fields were identified as forest or pasture and were excluded from the analysis since it was not clear from the records whether these fields had been converted into those uses from cropland.

The USDA NRCS conservation practices documented in the LREW CPD were implemented either with the cost shared as a component of a federally funded conservation program (Cost share) or with the cost assumed by the producer (Voluntary) with technical assistance provided by the USDA NRCS. All personal information was eliminated from the dataset to protect the privacy rights of the landowner.

The USDA SSURGO database contained information on hydrologic group (USDA 2007). A field-specific hydrologic group rating was determined by intersecting the SSURGO database with field boundaries derived from the LREW CPD. The output table was exported to a spreadsheet, and those groups that comprised $25 \%$ or more of the field area were concatenated to produce hydrologic group ratings. This allowed for the possibility of all four hydrologic groups $(\mathrm{A}, \mathrm{B}, \mathrm{C}$, and D) being represented in a single field (figure 2). Field-specific hydrologic group ratings were then appended to the LREW CPD database (figure 3).

A raster slope map was derived using $30 \mathrm{~m}$ (98 ft) digital elevation maps and the spatial analyst tool in ArcMap 9.2 (ESRI 2001). An average slope per field was calculated using the zonal attribute function and field boundaries derived from the LREW CPD. Raster outputs were then converted to shapefile format (point) and spatially were joined back 


\section{Figure 2}

Multiple hydrologic groups and soil units in a single field in the Little River Experimental watershed study area. Groups A and B had moderate to high infiltration, while groups C and D had very slow infiltration.

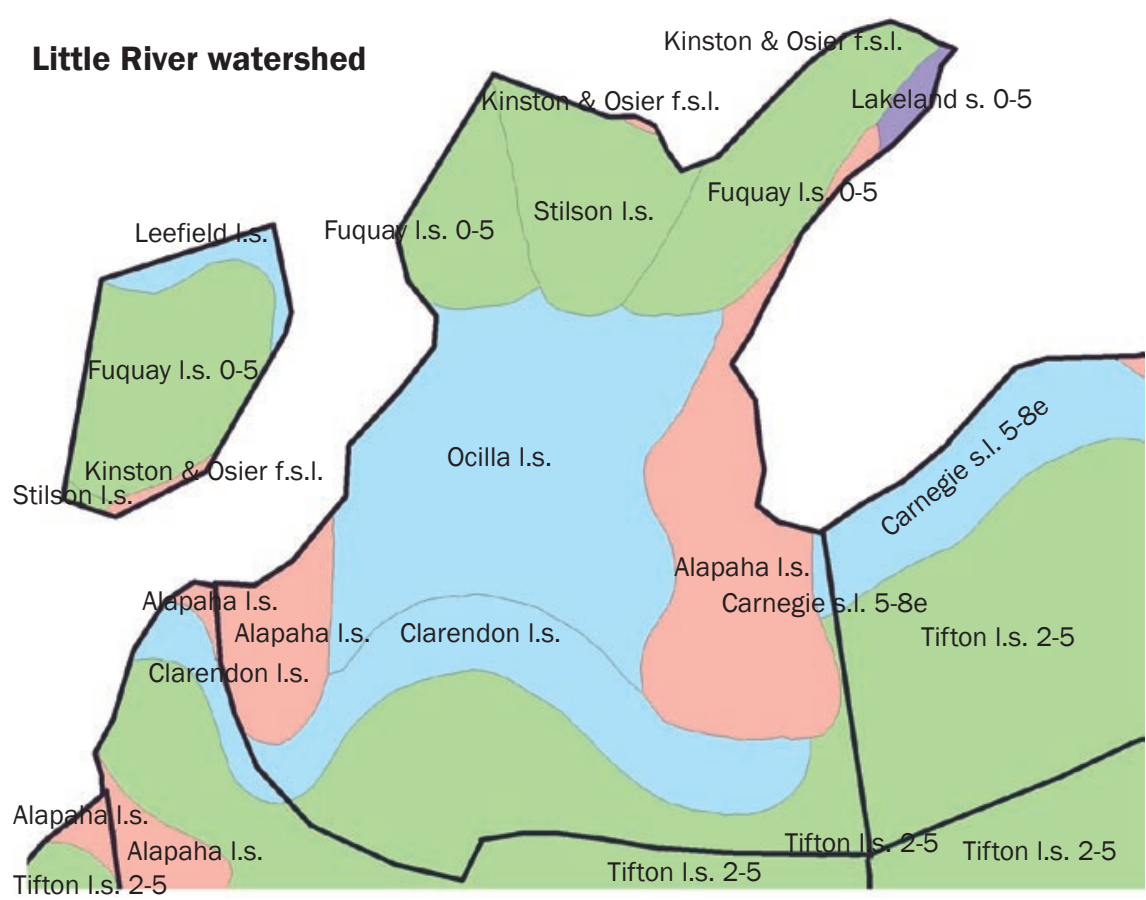

\section{Legend}

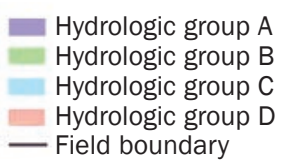

Notes: I.s. $=$ loamy sand. f.s.l. = fine sandy loam. s = sand. $0-5=0 \%$ to $5 \%$ slope.

$5-8 e=5 \%$ to $8 \%$ slope, eroded. $2-5=2 \%$ to $5 \%$ slope.

to the boundary databases. This essentially added an "average field slope" parameter to the boundary database (figure 3).

A second LREW database (subwatershed) had been created from a windshield survey of current cropping practices. Complete coverage of all cropland fields in four subwatersheds (J, K, N, and O) of the LREW were delineated using 2005 US Geological Survey digital orthoquads (DOQ) (figure 1). The subwatershed database provided a more representative sampling of the LREW since all cropland fields $(n=365)$ in the subwatershed database were delineated, regardless of their possible participation in USDA NRCS conservation programs.

Conservation Practice Assessment in the Little River Experimental Watershed Conservation Practice Database. The implementation of conservation practices was first evaluated broadly to identify general trends. Based on this analysis, soil erosion control and water quality protection practices were found to be the predominant practices used within the LREW. The database was then queried to determine whether or not conservation practices specific to soil erosion and water quality were placed in fields considered to be a high resource concern. Criterion for defining high resource concern areas within the LREW were based on slope, proximity (within $50 \mathrm{~m}$ [164 ft]) to a water feature, and hydrologic class. The GIS tool was employed to query the database to identify fields under the following high resource concern scenarios:

1. High risk of erosion (slope $>2.7 \%$, low infiltration)

2. High risk of erosion plus high surface runoff near water (proximate to water, slope $>2.7 \%$, low infiltration)

3. High risk of water quality degradation (proximate to water, slope $<2.7 \%$, high infiltration)
Slope values in the LREW ranged from $0 \%$ to $9 \%$ and were categorized into five classes using the Jenks natural breaks option in Environmental Systems Research Inc. ArcView (table 1). The Jenks classification is an iterative approach that compares observed class values to class means. Class breaks are determined when the within-class variation reaches a minimum. Soil units that contain slopes as low as $2 \%$ might be considered a hazard for cropland in the LREW (USDA NRCS 1983). In this study, a natural break in the data fell at a slope of $2.7 \%$ (slope classes 3,4 , and 5) and was used to define an erosion risk.

All fields within $50 \mathrm{~m}$ (164 ft) of a hydrologic feature (streams, ponds, reservoirs, and lakes) were identified using a US Geological Survey 7.5 minute topographic quadrangle sheet (Sullivan et al. 2007). The selection of $50 \mathrm{~m}$ was based on the approximate average width of riparian buffers in this region. Fields with a portion of their boundary within the $50 \mathrm{~m}$ buffer were considered "proximate to water." The field-specific hydrologic group ratings $\mathrm{A}, \mathrm{B}$, and $\mathrm{AB}$ were classified as "high infiltration," those containing any combination of $\mathrm{C}$ and $\mathrm{D}$ were classified as "low infiltration."

All practices specific to erosion control were evaluated using a series of linear regression analyses using the Statistical Analysis System (SAS Institute 1980).

Results were used to determine the likelihood that erosion control practices would increase as slope increased. Since individual fields often had multiple practice implementations, a second regression was conducted to determine if the frequency of conservation practice placement (dependent variable) increased with slope (independent variable). In other words, this analysis determined whether or not slope was linearly related to the intensity of conservation practice adoption.

Conservation Practice Assessment in the Subwatershed Database. Inclusion of fields in the subwatershed database was not predicated upon participation in USDA NRCS programs. Therefore, there was no preconceived expectation of erosion control practice implementation in the subwatershed database.

Since conservation practice histories were not available for all fields within the subwatersheds, practice adoption was assigned visually. Practice adoption was determined by super- 
Figure 3

Algorithm for creation of a geographic information system-based decision support tool database.

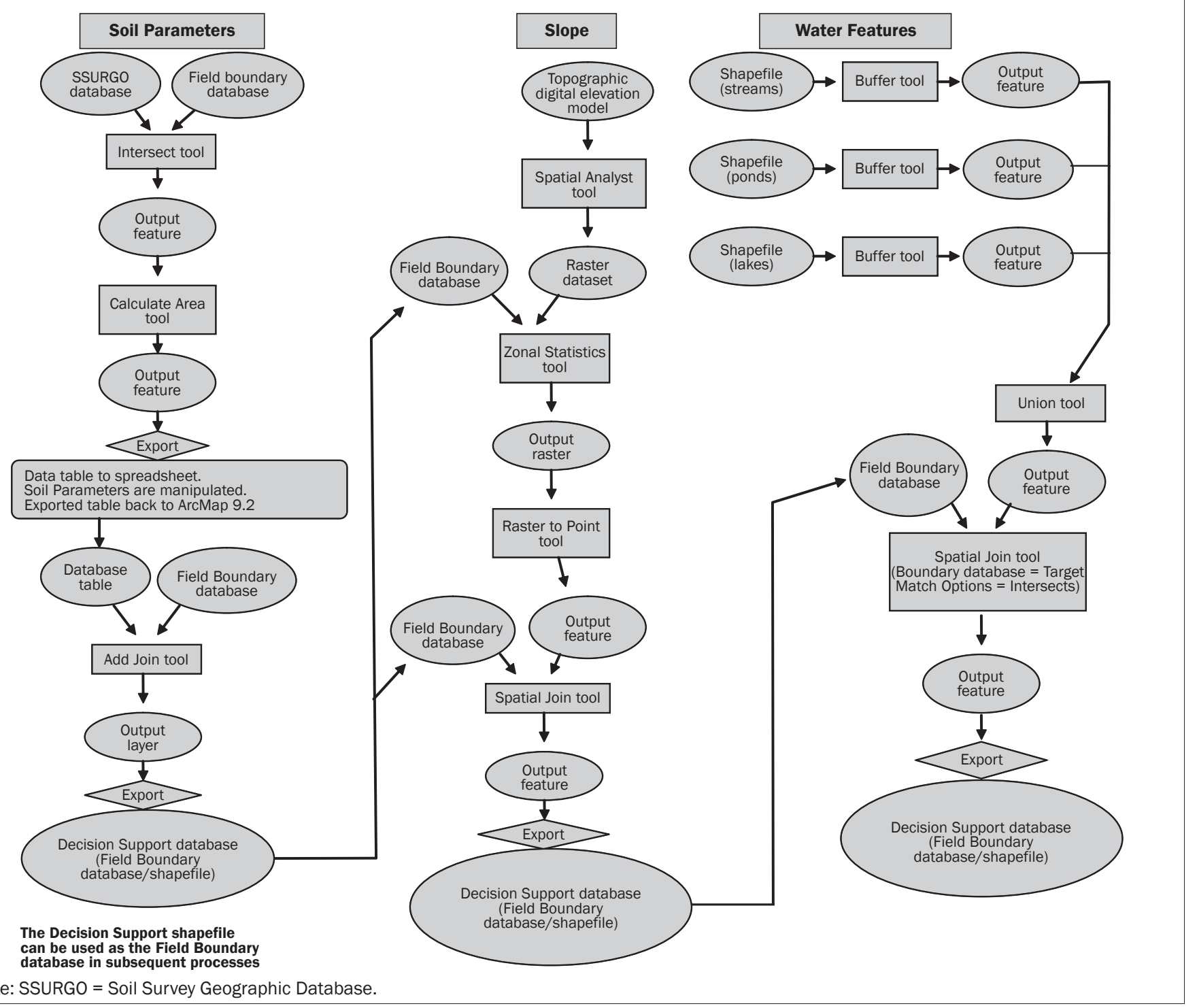

\section{Table 1}

Conservation practice implementations for all fields within the Little River Experimental Watershed Conservation Practice Database (LREW CPD) sorted by slope value (\%), slope class, all practices, erosion control practices, number of fields, and total acreage.

\begin{tabular}{|c|c|c|c|c|c|}
\hline \multirow[b]{2}{*}{ Slope values } & \multirow[b]{2}{*}{ Slope class } & \multirow{2}{*}{$\begin{array}{l}\text { All conservation practices } \\
\text { Implementations }\end{array}$} & \multicolumn{3}{|c|}{ Erosion control practices } \\
\hline & & & Implementations & Fields & Area (ha) \\
\hline $0.0 \%$ to $1.8 \%$ & 1 & 137 & 70 & 29 & 178.3 \\
\hline Lower concern & & 787 & 451 & 143 & $1,718.3$ \\
\hline $4.7 \%$ to $9.3 \%$ & 5 & 64 & 34 & 14 & 48.4 \\
\hline Higher concern & & 793 & 453 & 177 & $1,660.4$ \\
\hline Totals & & 1,580 & 904 & 320 & $3,378.7$ \\
\hline
\end{tabular}


imposing field boundaries on a 2005 DOQ, which was then examined for evidence of contour farming, terraces, or grassed waterways. These were the only USDA NRCS conservation practices that could be visually confirmed. It was assumed that producers implementing the conservation practices in 2005 would continue to utilize them in 2008 . These data allowed a comparative analysis of fields that implemented conservation practices with those that did not. This analysis could not be done with fields in the LREW CPD database, which by default,implemented conservation practices.

The subwatershed database was first analyzed to evaluate the overall placement of visible conservation practices with regards to slope. Second, as with the CDP-LREW, the high resource concern croplands in the subwatershed database were evaluated for conservation practice adoption using average field slope, proximity to water, and hydrologic group to define a high resource concern area. An additional parameter, soil erosion factor $(\mathrm{k})$, was obtained from the SSURGO database and was used to further delineate high resource concern areas. A $\mathrm{k}$ value of $>0.23$ was selected as a means to reduce the number of fields that were initially identified as having higher soil erosion potential.

The GIS tool was employed to identify fields under the following scenarios:

1. Risk of high erosion (slope $>2.7 \%$, low infiltration, $\mathrm{k}$ factor $>0.23$ )

2. High risk of water quality degradation due to runoff (slope $>2.7 \%$, proximate to water, low infiltration, $\mathrm{k}$ factor $>0.23$ ) or subsurface lateral flow (slope $<2.7 \%$, proximate to water, high infiltration)

Linear regression analysis was again conducted using Statistical Analysis Systems to determine the likelihood of visually identified erosion control-specific practices being implemented as slope class increased. For the regression analysis, the dependent variable was the percentage of erosion control practices that were adopted within each slope class, and the independent variable was slope class.

\section{Results and Discussion}

Little River Experimental Watershed Conservation Practice Database Overview. Croplands participating in conservation programs with USDA NRCS assistance represent $15 \%$ of the total land area and approximately $50 \%$ of all croplands in the LREW. Predominant practices included pest management, tree/shrub establishment, nutrient management, residue management (RM), contour farming (CF), grassed waterways $(\mathrm{GW})$, terraces $(\mathrm{T})$, and conservation cover (CC). These practices comprised 91\% of all observed practices and were primarily implemented under the following USDA NRCS programs: Conservation Reserve Program, Environmental Quality Incentives Program, Public Law 566 (Little River Watershed), and the Conservation Security Program. Field borders, water management, and soil management constituted the remaining $9 \%$ of practices.

Based on the historic trend in conservation practice adoption, soil erosion control and water quality were evaluated as primary resource concerns within the LREW. Residue management, CF, GW, T, and CC are conservation practices specified by the USDA NRCS for soil erosion problems in cropland settings (USDA NRCS 1996). Pest management and nutrient management practices have implications for water quality.

There were 1,580 practices implemented across the watershed with an average of three practices implemented per field and a maximum of 15 . Regression analysis conducted between frequency of conservation practice implementation per field and slope indicated no significant relationship. The fields with higher slopes, therefore, did not receive proportionally more conservation practices than those with less slope. The multiple implementations per field may have been due to other factors, such as changing federal program offerings, the imposition of "suites" of practices on any single field, and/or to a single field receiving increased levels of conservation adoption over the 26-year period (M. Leidner, USDA NRCS, personal communication 2008). Multiple implementations per field also complicated an acreage analysis of conservation practices, often resulting in misleading comparisons. Preliminary assessments, however, showed that results based on field numbers rather than acreage were similar. Thus, to maintain clarity, field numbers were used for most analyses.

Between 1980 and 2000, most conservation practices were voluntarily implemented with technical assistance provided by the USDA NRCS. Since 2000, however, federally funded conservation practices have exceeded voluntary adoption rates. Overall, $82 \%$ of all fields in the LREW CPD implemented at least one cost-shared practice, with more than $50 \%$ having more than one costshare practice. Of the 1,580 implemented practices, water and erosion control practices represented $46 \%$ of cost-shared implementations and $35 \%$ of voluntary implementations. The most commonly implemented erosion control practices, RM and CF, were implemented voluntarily over $88 \%$ of the time. They also have a low cost to the producer. Two higher cost practices, GW and $\mathrm{T}$, were implemented as a cost share with the USDA NRCS $82 \%$ and $75 \%$ of the time, respectively.

Resource Concern 1: High Risk for Erosion. The database was queried to identify all fields with slopes $>2.7 \%$. Table 1 shows that while $55 \%$ (177) of fields fell into the high resource concern slope category (slope classes 3, 4, and 5), the actual number of erosion control practices implemented was nearly equally distributed between low resource concern and high resource concern fields. Specific conservation practices, however, were preferentially adopted based on slope class. Residue management and CF were the preferred erosion control practices (45.8\% of implementations) for sites having an average slope of $<3.5 \%$ (table 2) (preference for implementation was $\mathrm{RM}>\mathrm{CF}>$ $\mathrm{GW}>\mathrm{T}>\mathrm{CC})$. Conservation cover and RM were preferred (48.7\% of implementations) on fields with an average slope $>3.5 \%$ (preference for implementation was RM > $\mathrm{CC}>\mathrm{CF}>\mathrm{GW}=\mathrm{T}$ ).

Regression analysis between slope class and percent practice implementation showed no significant relationship existed between practice implementation and slope class (table 3). Analyses of individual erosion control practices, however, showed that for residue management, a significant relationship existed between practice placement and slope class $\left(r^{2}=0.69\right.$, alpha $\left.=0.10\right)$. However, the slope of the line relating implementation and slope class was negative, indicating that as slope increased, residue management was less likely to be selected as a conservation practice.

Although the placement of erosion control practices on fields in slope class 1 would appear to suggest inefficient use of USDA NRCS resources, it is more likely that other factors come into play. For instance, fieldspecific slopes are calculated averages, and 
Table 2

The number (and percentage) of specific erosion-control practices implemented in five slope classes.

\begin{tabular}{|c|c|c|c|c|c|c|c|}
\hline Slope values & $\begin{array}{l}\text { Slope } \\
\text { class }\end{array}$ & $\begin{array}{l}\text { Residue } \\
\text { management }\end{array}$ & $\begin{array}{l}\text { Contour } \\
\text { farming }\end{array}$ & $\begin{array}{l}\text { Grassed } \\
\text { waterway }\end{array}$ & Terrace & $\begin{array}{l}\text { Conservation } \\
\text { cover }\end{array}$ & Total \\
\hline $0.0 \%$ to $1.8 \%$ & 1 & 19 (27.1\%)* & 11 (15.7\%) & $10(14.3 \%)$ & 12 (17.1\%) & 18 (25.7\%) & 70 (100\%) \\
\hline $2.7 \%$ to $3.5 \%$ & 3 & 74 (24.9\%) & 62 (20.9\%) & 56 (18.9\%) & 56 (18.9\%) & 49 (16.5\%) & 297 (100\%) \\
\hline $3.5 \%$ to $4.7 \%$ & 4 & 26 (21.3\%) & $22(18.0 \%)$ & 22 (18.0\%) & 21 (17.2\%) & 31 (25.4\%) & $122(100 \%)$ \\
\hline
\end{tabular}

* Percentages are within slope classes.

\section{Table 3}

Logistical regression results showing the relationship between water erosion control practice adoption (dependent) variable and slope class (independent) variable (alpha $=0.10$ ).

\begin{tabular}{|c|c|c|c|}
\hline Dependent variable & $r^{2}$ & Slope & $\operatorname{Pr}>F^{*}$ \\
\hline $\begin{array}{l}\text { Percent of all cropland conservation practices that were specified as } \\
\text { USDA Natural Resources Conservation Service erosion control techniques }\end{array}$ & 0.01 & -0.33 & 0.85 \\
\hline Percent of erosion control practices that were contour farming & 0.01 & 0.13 & 0.88 \\
\hline Percent of erosion control practices that were grassed waterways & 0.11 & -0.72 & 0.59 \\
\hline Percent of erosion control practices that were terraces & 0.35 & -0.66 & 0.29 \\
\hline
\end{tabular}

* Probability level that the test statistic is greater than the expected $\mathrm{F}$ value in a Statistical Analysis Systems analysis.

there may be areas within a field that have relatively high slopes. In addition, erosion control practices, such as RM and CC, also provide soil quality benefits, such as increased soil organic carbon content, increased plant available water, and a reduction in off-site transport of agrochemicals (Reeves 1997; Franzeubblers 2001; Truman and Rowland 2005). It is not surprising, therefore, that slope class alone was not the best indicator of erosion control practice adoption. In fact, RM and CC represent $43 \%$ of erosion control practices implemented in the watershed (table 2) and were commonly implemented voluntarily by landowners.

Since slope class alone was a poor indicator of erosion control practice placement, the database query was expanded to include fields having a low infiltration rate and a slope greater than $2.7 \%$. There were 10 field-specific hydrologic groupings observed, ranging from moderate to high infiltration (groups A, $B$, and $A B)$ to very slow infiltration $(C, D$, $\mathrm{CD})$. Most fields were characterized as having high to moderately high infiltration rates, while nearly 23\% were identified as having at least a portion of their area with slow to very slow infiltration (including hydrologic groups $\mathrm{C}$ or $\mathrm{D})$.
In total, 73 fields met the criterion of having an average field slope $>2.7 \%$ and a hydrologic group designation that included groups $\mathrm{C}$ and/or D. Erosion control practices were implemented on $62 \%$ of these fields (45 fields), accounting for $77 \%$ of the at-risk land area. Categorical frequency data analysis (Steele and Torrie 1980) indicated that erosion control practices were not randomly assigned to fields with a higher risk $\left(x^{2}=3.5\right.$, $p=0.06)$.

The results suggest that conservation program priorities were established based on the combined effects of increasing slope and decreasing infiltration rates. Keep in mind that these "at-risk" fields constituted only $23 \%$ of all fields in the LREW CPD. Because soils in the LREW are predominantly well drained and gently sloping, it is not surprising that conservation efforts were more concentrated in at-risk fields. The placement of erosion control practices in well-drained soils suggests that reasons other than erosion control, such as soil quality, cost, and perceived effectiveness, may be driving those decisions.

Resource Concern 2: High Risk of Erosion Plus High Surface Runoff Proximate to Water. When water quality concerns were included as a factor in conservation practice placement, $68 \%$ of fields in the LREW CPD, accounting for 3,541.8 ha (8,752 ac) were proximate to a water feature. As previously observed for sites considered at risk for erosion only, there was no significant linear relationship between the occurrence of erosion control practices and slope class. Implementations were evenly divided between high-slope and low-slope fields (table 4), with $56 \%$ of conservation practices specific to erosion control. Analysis of specific erosion control practices did not improve this relationship.

In an attempt to better isolate fields at risk for erosion and degradation of water quality, a hydrologic group rating was again added to the query. When all fields proximate to a water feature with slopes $>2.7 \%$ and slow to very slow infiltration were selected, 48 fields (397.8 ha (983 ac]) were identified. Of these sites, 29 fields, or $60 \%$, had implemented at least one erosion control-specific practice; some had implemented as many as six.

Resource Concern 3: High Risk of Water Quality Degradation. Water quality concerns were not limited to erosion and sedimentbound off-site transport of agrochemicals. In keeping with the observations of Hubbard 
Table 4

Conservation practice implementations for all fields within the Little River Experimental Watershed Conservation Practice Database (LREW CPD) that are within $50 \mathrm{~m}$ of a water body. Data are sorted by slope value (\%), slope class, all practices, erosion control practices, number of fields, and total acreage.

\begin{tabular}{|c|c|c|c|c|c|c|c|}
\hline \multirow[b]{2}{*}{ Slope class } & \multirow{2}{*}{$\begin{array}{l}\text { Total conservation } \\
\text { practices implemented }\end{array}$} & \multicolumn{3}{|c|}{ Erosion control practices } & \multicolumn{3}{|c|}{ Water quality practices } \\
\hline & & Implementations & Fields & Area (ha) & Implementations & Fields & Area (ha) \\
\hline 1 & 79 & 39 & 16 & 137.2 & 35 & 20 & 175.1 \\
\hline 2 & 495 & 288 & 83 & $1,253.3$ & 156 & 68 & 995.0 \\
\hline Low slope & 574 & 327 & 99 & $1,390.5$ & 191 & 88 & $1,170.1$ \\
\hline 3 & 398 & 233 & 83 & $1,061.8$ & 121 & 56 & 685.2 \\
\hline 4 & 147 & 72 & 30 & 242.7 & 62 & 29 & 204.2 \\
\hline 5 & 43 & 20 & 8 & 32.6 & 19 & 9 & 26.3 \\
\hline High slope & 588 & 325 & 121 & $1,337.1$ & 202 & 94 & 915.7 \\
\hline Total & 1,162 & 652 & 220 & $2,727.6$ & 393 & 1,821 & $2,085.8$ \\
\hline
\end{tabular}

and Sheridan (1983) that lateral subsurface flow is a substantial hydrologic component in the LREW, consideration was also given to the potential for transmission to groundwater or subsurface lateral flow using parameters of high to moderately high infiltration hydrologic groupings coupled with slopes $<2.7 \%$ and proximate to a water feature. This produced a list of 110 fields $(1,538.6$ ha $[3,802$ ac]) on which there were 471 implementations of 12 different conservation practices. The predominant conservation practices consisted of nutrient management and pest management (178 implementations on 71 fields), both of which are designed to improve water quality via appropriate use of nutrient, organics, and pesticides (USDA NRCS $2006 \mathrm{a}, 2006 \mathrm{~b})$. In total, $65 \%$ of the at-risk fields implemented appropriate conservation practices, averaging 2 to 3 practices per field.

Conservation Practice Placement in the Subwatershed Database. A broad assessment of conservation practice placement was conducted using the subwatershed database. This dataset differs from the LREW CPD in that it contains fields that may not have implemented conservation practices and may not have participated in USDA NRCS programs. The subwatershed database contained 365 fields, of which 104 (28\%) had received some form of USDA NRCS conservation practice assistance.

The subwatershed database was first analyzed to evaluate the overall placement of visible conservation practices (CF, T, and GW) with regards to slope. For this assessment, only erosion control practices visible from a 2005 DOQ were evaluated. Visual analysis of the fields in the subwatershed database indicated that 129 fields (35\%) had implemented CF, T, or GW.
Linear regression between slope class and visible conservation practices produced an $r^{2}$ value of 0.64 with a slope of 6.68 (probability level $[\mathrm{Pr}]<0.10)$, indicating that as slope increased, there was a higher percentage of fields implementing these conservation practices. In contrast to the LREW CPD, where we analyzed all erosion control practices using a database in which all fields received some form of USDA NRCS assistance, slope class appears to correspond well with the adoption of visible erosion control practices in the subwatershed database. Results suggest that the adoption of CF, T, and GW is more likely based on necessity (highly erodible lands), rather than availability of conservation program assistance.

As with the CDP-LREW, the high resource concern croplands in the subwatershed database were queried to evaluate conservation practice placement. The first scenario was for fields at risk for soil erosion. The subwatershed database was queried to select fields having an average slope $>2.7 \%$, hydrologic groups containing $\mathrm{C}$ and/or D designations, and an erosion factor $(\mathrm{k})>0.23$. This resulted in a list of 78 at-risk fields, of which $47 \%$ implemented visible erosion control-specific conservation practices. The sites implementing erosion control practices can be further broken into two classes: those receiving USDA NRCS assistance $n=23$ and those implementing practices on their own $n=14$. While this data shows that federally funded erosion control practices are 1.6 times more likely to be implemented than voluntarily adopted practices, it also indicates environmental stewardship on behalf of the landowner in the absence of federally funded conservation practice assistance.

The second scenario evaluated fields at risk for water quality degradation due to the potential for runoff or subsurface flow. Since not all practices to improve water quality are visible from a DOQ, the main purpose of this analysis was to quantify the number of fields at risk and how many had received USDA NRCS assistance. The first condition imposed for this scenario was proximity to a water feature, which reduced the number of eligible fields to 200. Then imposing the two combinations of parameters yielded a total of 74 fields. Twenty-six of these fields (35\%) were also part of the historical practice database and, therefore, had received some form of USDA NRCS assistance.

\section{Summary and Conclusions}

As a benchmark watershed in the CEAP WAS initiative, the LREW is a valuable resource, rich in data on historic land use, hydrologic records, and conservation practice implementation. The analysis of historical conservation practice placement can provide insights to policymakers for the development of new programs, as well as provide a foundation for optimizing future practice placement for maximum soil and water conservation benefits. Using the documented conservation practice history embodied in the LREW CPD it was possible to determine predominant practices and evaluate practice placement in the context of soil and landscape features.

This study also illustrates the potential use of a GIS decision-making tool for the placement and evaluation of conservation practices. It allows users to define high resource concern fields in databases. In the first case, we applied the tool posthoc to evaluate 26 years of conservation practice establishment in a historical database. This allowed for an evaluation of the effectiveness of introduced conservation 
practices or farming systems and to monitor program implementation

Results from our analysis indicated that a minimum of $60 \%$ of fields in the LREW CPD implemented appropriate practices for three selected water erosion and water quality scenarios. The remaining $40 \%$ may have been driven by the desire for basic soil quality benefits, conservation program availability, belief in the effectiveness of a practice and/or belief about the cost of a practice, to name a few. While these reasons are beyond the scope of the current study, a portion of the $40 \%$ may also have been misclassified as a low resource concern area, considering that all our estimates were based on average field values and within-field variability may have been a factor in conservation adoption. There was insufficient data resolution to account for within-field variability.

We also applied the GIS tool as a means to identify at-risk fields from a more representative population of fields from a subwatershed database within the LREW. Results from this analysis indicated that 53\% of the fields that we defined as at risk had not employed visible conservation practices. These fields would be prime candidates for conservation outreach efforts. By allowing the user to define high resource concerns, the selection of fields for inclusion in conservation programs could be streamlined, and scarce resources could be deployed more effectively.

The creation of STEWARDS and the LREW CPD, along with more commonly available natural resource databases, such as SSURGO, have created opportunities by which to drive the efficiency of conservation practice placement, monitor conservation programs, and evaluate new tools/strategies for natural resource management. Results from this analysis indicated a high rate of appropriate conservation practice placement in the LREW and identified areas of additional opportunity to conserve soil and water resources in the future.

\section{References}

Bosch, D.D., and J.M. Sheridan. 2007. Stream discharge database, Little River Experimental Watershed, Georgia, United States. Water Resources Research 43, W09473, doi:10.1029/2006WR005833.

Bosch, D.D., D.G. Sullivan, and J. Sheridan. 2006. Hydrologic impacts of land-use changes in coastal plain watersheds. Transactions of the American Society of Agricultural and Biological Engineers 49(3):423-432.
ESRI (Environmental Systems Research Inc). 2001 StreetMap USA. Redlands, CA: Environmental Systems Research.

Feyereisen, G.W., R.R. Lowrance, T.C. Strickland, D.D. Bosch, and J.M. Sheridan. 2008. Long-term stream chemistry trends in the southern Georgia Little River Experimental Watershed. Journal of Soil and Water Conservation 63(6):475-486, doi:10.2489/jswc.63.6.475.

Feyereisen, G.W., R. Lowrance, T.C. Strickland, J.M Sheridan, R.K. Hubbard, and D.D. Bosch. 2007 Long-term water chemistry database, Little River Experimental Watershed, southeast coastal plain, United States. Water Resources Research 43, W09474, doi:10.1029/2006WR005835.

Franzuebblers, A.J. 2001. Water infiltration and soil structure related to organic matter and its stratification depth. Soil \& Tillage Research 66:97-205.

Hatfield, J.L., D.A. Bucks, E.E. Albert, R.H. Dowdy, N.R. Fausey, and J.L. Schepers. 2002. Assessment of the Water Quality Impacts of Farming Systems by Integrating Databases and Simulation Models. Proceedings National Water Quality Monitoring Council. May 20-23, 2002, Madison, Wisconsin.

Hubbard, R.K., and J.M. Sheridan. 1983. Water and nitrate-nitrogen losses from a small, upland, coastal plain watershed. Journal of Environmental Quality 12:291-295.

Lowrance, R.R., R.A. Leonard, L.E. Asmussen, and R.L. Todd. 1985. Nutrient budgets for agricultural watersheds in the southeastern coastal plain. Ecology 66(1):287-296.

Mausbach, M.J., and A.R. Dedrich. 2004. The length we go: Measuring environmental benefits of conservation practices. Journal of Soil and Water Conservation 59(5):96A-103A.

Reeves, D.W. 1997. The role of soil organic matter in maintaining soil quality in continuous cropping systems. Soil \& Tillage Research 43:137-167.

Sadler, E.J., J.L. Steiner, J.S. Chen, G. Wilson, J. Ross, T. Oster, D. James, B. Vandenberg, K. Cole, and J. Hatfield. 2008. Sustaining the earth's watersheds-Agricultural Research Data System: Data development, user interaction, and operations management. Journal of Soil and Water Conservation 63(6):577-589, doi:10.2489/jswc.63.6.577.

SAS (Statistical Analysis Systems) Institute. 1980. SAS User's Guide, 1982 edition. Cary, NC: Statistical Analysis Systems Institute.

Soil and Water Conservation Society. 2006. Final Report from the Blue Ribbon Panel Conducting an External Review of the U.S. Department of Agriculture Conservation Effects Assessment Project (CEAP). Ankeny, IA: Soil and Water Conservation Society.

Steel, R.C.D., and J.H. Torrie. 1980. Principles and Procedures of Statistics, 2nd ed. New York: McGraw-Hill.
Steiner, J.L., E.J. Sadler, J.S. Chen, G. Wilson, D. James, B. Vandenberg, J. Ross, T. Oster, and K. Cole. 2008. Sustaining the earth's watersheds-Agricultural Research Data System: Overview of development and challenges. Journal of Soil and Water Conservation 63(6):569-576, doi:10.2489/jswc.63.6.569.

Sullivan, D.G., and H.L. Batten. 2007. Little River Experimental Watershed, Tifton, Georgia, United States: A historical geographic database of conservation practice implementation. Water Resources Research 43, W09475, doi:10.1029/2007WR006143.

Sullivan, D.G., H.L. Batten, D. Bosch, J. Sheridan, and T. Strickland. 2007. Little River Experimental Watershed, Tifton, Georgia, United States: A geographic database. Water Resources Research 43, W09471, doi:10.1029/2006WR005836

Truman, C.C., and D.L. Rowland. 2005. Conservation tillage to manage water and supplemental irrigation in Georgia. In Proceedings of the 2005 Georgia Water Resources Conference, University of Georgia Institute of Ecology, ed. K.J Hatcher. Athens, Georgia. April 25-27, 2005.

USDA NRCS (Natural Resources Conservation Service). 1983. Soil Survey of Tift County. USDA Natural Resource Conservation Service.

USDA NRCS. 1996. Agroforestry for Farms and Ranches. Agroforestry Technical Note No. 1, July 1, 1996. http:// www.nrcs.usda.gov/technical/ECS/forest/technote.html.

USDA NRCS. 2006a. National Handbook of Conservation Practices (NHCP) ftp://ftp-fc.sc.egov.usda.gov/NHQ/ practice-standards/cppe/matrix/590cppe.doc.

USDA NRCS. 2006b. National Handbook of Conservation Practices (NHCP). ftp://ftp-fc.sc.egov.usda.gov/NHQ/ practice-standards/cppe/matrix/595cppe.doc.

USDA NRCS. 2007. Soil Survey Geographic (SSURGO) Database. USDA Natural Resources Conservation Service Soil Data Mart. http://soildatamart.nrcs.usda.gov. 